\title{
Critical indices of the ferroelectric phase transition in TGS crystals
}

\author{
O.Myshchyshyn, B.Andriyevsky, M.Romanyuk \\ Ivan Franko State University of Lviv, \\ 8 Kyryla and Mefodiya Str., 290005 Lviv, Ukraine
}

Received January 13, 1999

Temperature dependencies of retardation, electron susceptibility and linear thermal expansion for three crystal-physic directions are obtained by means of optical investigations of the ferroelectric phase transition in TGS crystal using the James-type interferometer. Temperature dependencies of the spontaneous changes of the characteristics studied in the $39-49^{\circ} \mathrm{C}$ range are fitted by the power low $Y \sim \tau^{2 \beta}$ with double critical indices $2 \beta=0.87-0.95$. Difference of $2 \beta$ values from the unity is explained by the essential temperature dependence in the range close to the phase transition point for the coefficients of electrooptic, reversed piezoelectric and electrostriction effects.

Key words: ferroelectrics, phase transition, optical properties, critical indices

PACS: $77.80 . \mathrm{Bh}, 77.84 . \mathrm{Fa}, 78.20 . \mathrm{Ci}$

\section{Introduction}

It is known, that critical behaviour of spontaneous polarization $P_{\mathrm{s}}$ at the 2 nd order phase transition (PT) in a crystal is described by the critical index $\beta$,

$$
P_{\mathrm{s}} \sim\left(T_{\mathrm{c}}-T\right)^{\beta}
$$

where $T_{\mathrm{c}}$ is the PT temperature [1].

Temperature dependencies of the refractive indices and linear thermal expansion of TGS in the range of PT have already been studied [2-4], but the corresponding critical indices have not been determined.

The goals of the present investigation were precise measurements of temperature dependencies of interferometric retardation of the sample-air type for the TGS in the range of 2 nd order $\mathrm{PT}$ at $322 \mathrm{~K}$, calculating the temperature dependencies of refractive indices and linear thermal expansion for the main crystallophysic directions of the crystal, as well as studying these dependencies using the corresponding critical indices $2 \beta$. 


\section{Methods, results and discussion}

Temperature dependencies of retardation by the susceptibility $\eta$ for two interfering beams, one of which has passed through a sample studied, and the other one through the air, were measured using the home built Jamen type interferometer. In this case the retardation $D$ can be written in the form

$$
D=l \cdot(n-1)=l \cdot \eta,
$$

where $n$ is the refractive index of the sample. The laser light of the wavelength $\lambda=632.8 \mathrm{~nm}$ was used in the experiments.

Proceeding from the relation (2), the temperature changes of relative retardation $\Delta D / D$ along the three crystallophysic directions can be written in the form of a system of linear equations

$$
\begin{aligned}
\frac{\Delta D_{i j}}{D_{i j}}= & \frac{\Delta l_{i}}{l_{i}}+\frac{\Delta \eta_{j}}{\eta_{j}}, \\
& (i, j=1,2,3 ; \quad i \neq j),
\end{aligned}
$$

where index $i$ denotes the direction of light propagation, index $j$ denotes the direction of light polarization. Based on the six temperature dependencies $\Delta D_{i j} / D_{i j}$ measured we have determined the relative temperature changes of geometric thickness $\Delta l_{i} / l_{i}$ and susceptibility $\Delta \eta_{j} / \eta_{j}[5]$. Results of the computer calculations have shown, that the relative errors of determining the temperature changes of geometric thickness $\delta l_{i} / l_{i}$ and susceptibility $\delta \eta_{j} / \eta_{j}$ after solving the system (3), did not exceed $5 \%$ of the respective maximum magni-

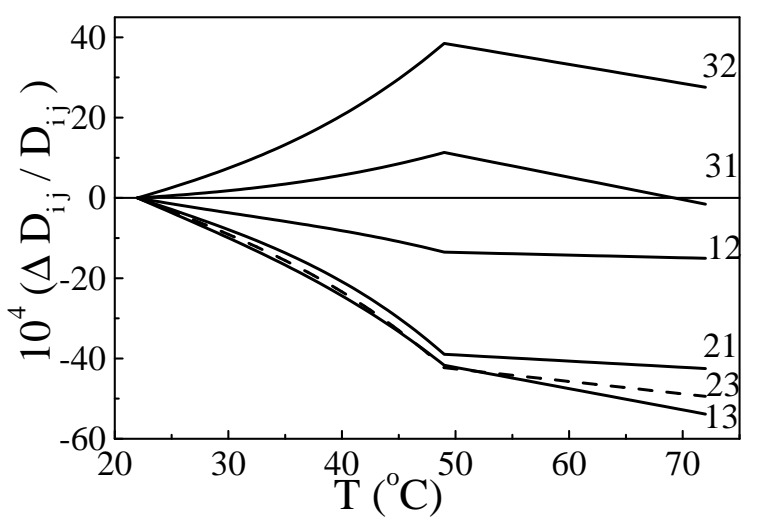

Figure 1. Experimental temperature dependencies of the relative changes of optical thickness $\Delta D_{i j} / D_{i j}$ of TGS crystal (indices $i j$ indicate the corresponding curves)

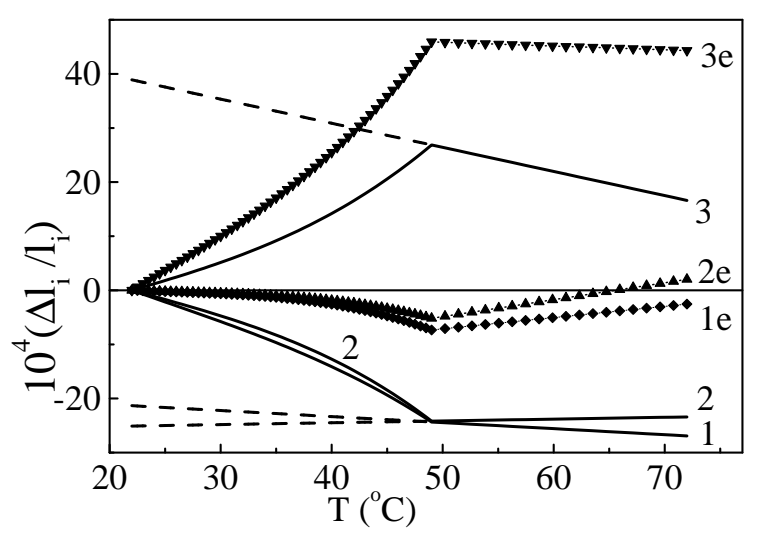

Figure 2. Calculated and experimental $(e)$ temperature dependencies of the geometric thickness changes $\Delta l_{i} / l_{i}$ of TGS crystal (indices $i$ indicate the corresponding curves) tudes $\Delta l_{i} / l_{i}$ and $\Delta \eta_{j} / \eta_{j}$ for the case of TGS crystal. The initial $l_{i}$ and $\eta_{j}$ values were measured independently at the initial temperature $T_{0}$. The error of determining the interference order was $\delta m(T) \leqslant 1 / 4$, that corresponds to the errors of $\delta D / D \sim \delta l / l \sim \delta \eta / \eta \sim 10^{-5}$ in our case $(l=5 \mathrm{~mm}$ and $n=1.5)$. Temperature dependencies of relative changes of retardation $\Delta D_{i j} / D_{i j}$ for TGS crystal are shown on figure 1 . 


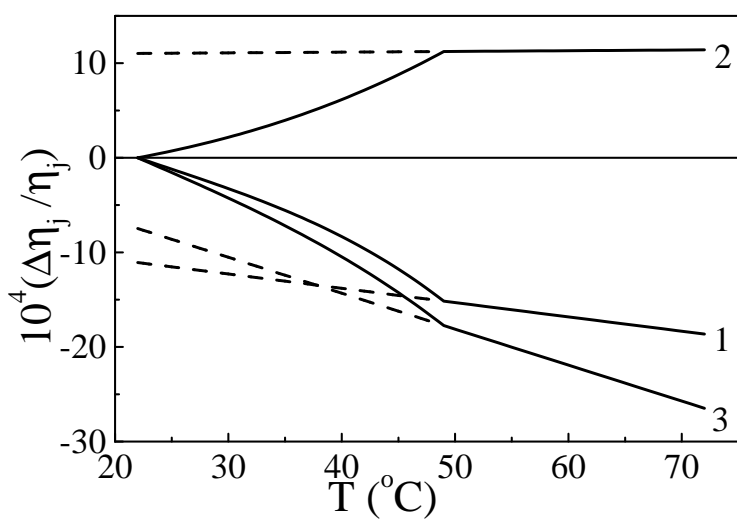

Figure 3. Calculated temperature dependencies of the refractive indices changes $\Delta n_{j} / n_{j}$ of TGS crystal (indices $j$ indicate the corresponding curves)

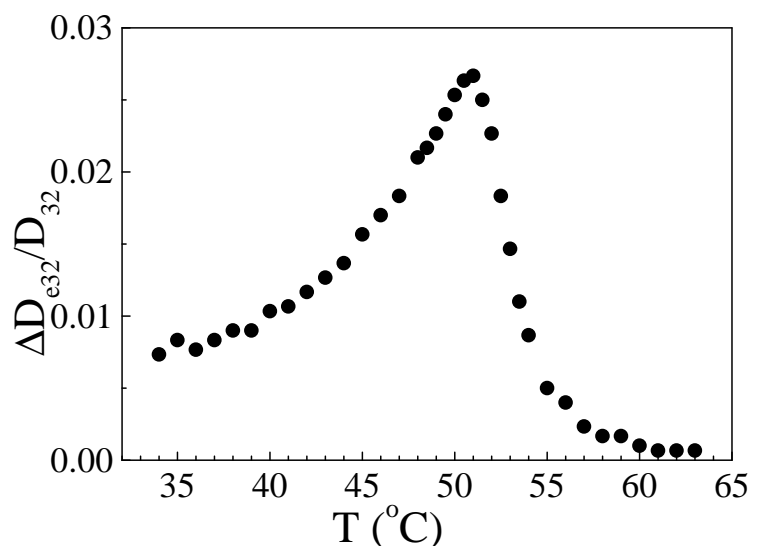

Figure 4. Temperature dependence of the relative optical path difference $\Delta D_{e 32} / D_{32}$ of TGS crystal induced by the constant electric field of $3.5 \mathrm{kV} / \mathrm{cm}$ magnitude along the [010]-direction
The temperature dependencies of the changes of the geometrical thickness $\Delta l_{i} / l_{i}$ and the refractive indices $\Delta n_{j} / n_{j}$ of the TGS crystal calculated using the system of equations (3) are shown in figures 2,3. The temperature dependencies of the calculated $\Delta l_{i} / l_{i}$ parameters (figure 2) agree satisfactorily with the results of experimental measurements of thermal expansion of TGS crystals obtained by us using a mechanical quartz dilatometer. The anisotropy of the spontaneous increases $\Delta l_{\mathrm{s}} / l$ calculated (figure 2) agrees well with the relationships between piezoelectric coefficients of TGS: $g_{22}>g_{21},\left|g_{23}\right|>g_{22}$, $\operatorname{sign} g_{22}=\operatorname{sign} g_{21}=-\operatorname{sign} g_{23}$ [6].

It follows from figures 2,3 , that the temperature dependencies of geometrical thickness and refractive indices for the same crystal physics directions are not similar in all cases. For example, a temperature increase of refractive index is observed for [010] direction of spontaneous polarization in TGS and a decrease of this parameter is observed for [100] and [001] directions (figure 3). The sign of the temperature changes of the geometrical thickness $\Delta l / l$ along the [010] direction (figure 2) is opposite to the sign of the corresponding $\Delta n / n$ changes (figure 3).

Based on the known relation for temperature changes of the order parameter $p$ for 2 nd order $\mathrm{PT}$ in the $T<T_{\mathrm{c}}$ range,

$$
\Delta Y_{\mathrm{s}} \sim P_{\mathrm{s}}^{2} \sim \tau^{2 \beta}=\left(\frac{T_{\mathrm{c}}-T}{T_{\mathrm{c}}-T_{\min }}\right)^{2 \beta},
$$

we have calculated the double critical indices $2 \beta$, replacing $P_{\mathrm{s}}^{2}$ value by the spontaneous increases of $\Delta Y_{\mathrm{s}}(T) / \Delta Y_{\mathrm{s}}\left(T_{\min }\right)(Y=D, l$ and $\eta)$. Here $T_{\mathrm{c}}=49^{\circ} \mathrm{C}$ is the temperature of PT, $T_{\min }$ is the lower edge of the temperature range studied $\left(T_{\min }=39^{\circ} \mathrm{C}\right.$ in our case), $\Delta Y_{\mathrm{s}}(T)$ and $\Delta Y_{\mathrm{s}}\left(T_{\min }\right)$ are spontaneous increments, corresponding to the $T_{\mathrm{c}}$ and $T_{\min }$ temperatures. The double critical indices $2 \beta$ for TGS in the range of $39-49^{\circ} \mathrm{C}$ are shown in table 1. 
Table 1. Critical indices $2 \beta$, corresponding to the temperature dependencies of spontaneous increments of $\Delta D_{\mathrm{s}} / D, \Delta l_{\mathrm{s}} / l$ and $\Delta \eta_{\mathrm{s}} / \eta$ for different crystallophysic directions $(i, j=1,2,3)$ of TGS crystal

\begin{tabular}{||c|c|c|c|c|c||}
\hline \hline $2 \beta_{12}^{(D)}$ & $2 \beta_{13}^{(D)}$ & $2 \beta_{21}^{(D)}$ & $2 \beta_{23}^{(D)}$ & $2 \beta_{31}^{(D)}$ & $2 \beta_{32}^{(D)}$ \\
\hline 0.899 & 0.898 & 0.888 & 0.893 & 0.945 & 0.924 \\
\hline \hline $2 \beta_{1}^{(l)}$ & $2 \beta_{2}^{(l)}$ & $2 \beta_{3}^{(l)}$ & $2 \beta_{1}^{(\eta)}$ & $2 \beta_{2}^{(\eta)}$ & $2 \beta_{3}^{(\eta)}$ \\
\hline 0.910 & 0.895 & 0.923 & 0.876 & 0.925 & 0.877 \\
\hline \hline
\end{tabular}

The results obtained testify to not exact fulfilment of functional dependencies for the quadratic electrooptic effect $\Delta n_{\mathrm{s}} \sim P_{\mathrm{s}}^{2}$ and electrostriction $\Delta l_{\mathrm{s}} \sim$ $P_{\mathrm{s}}^{2}$. If these effects were displayed in the form indicated, then the double critical index $2 \beta$ would be equal to unity, $2 \beta=1$. Therefore we have to explain the fact that $2 \beta$ values are different from the unity.

Analytical description of the observed temperature dependence of retardation $\Delta D_{\mathrm{s}} / D$ induced by spontaneous polarization can be presented in the most common form

$$
\Delta D_{\mathrm{s}} / D(\tau)=a(\tau) \cdot P_{\mathrm{s}}^{2}(\tau)=a(\tau) \cdot \tau
$$

where $a(\tau)$ is temperature dependent coefficient. It follows from the character of experimental dependencies of spontaneous increases of $\Delta D_{\mathrm{s}} / D, \Delta l_{\mathrm{s}} / l$, and

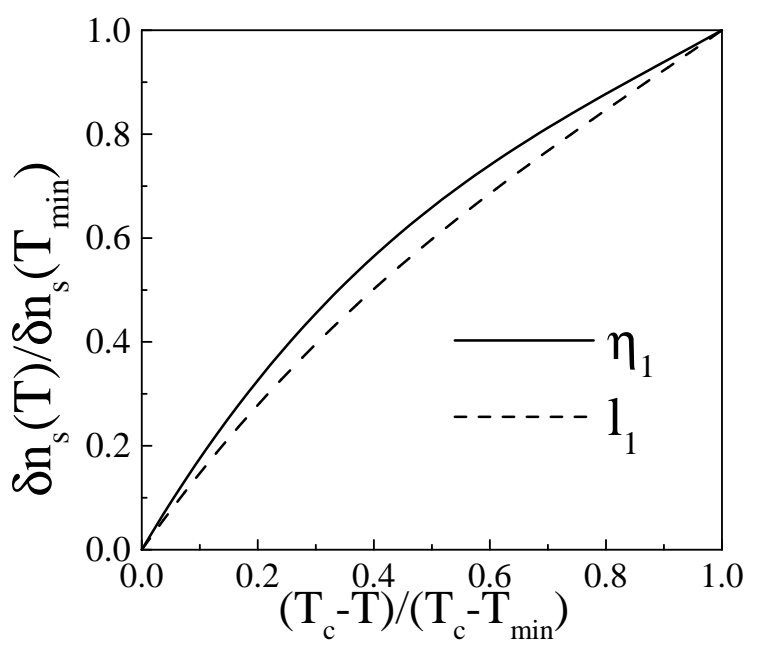

Figure 5. Dependencies of the normalised spontaneous changes of thickness $\left(l_{1}\right)$ and susceptibility $\left(\eta_{1}\right)$ of TGS for the [100] direction on the normalized temperature $\left(T_{\mathrm{c}}-T\right) /\left(T_{\mathrm{c}}-T_{\min }\right)$ in the range of $39-49^{\circ} \mathrm{C}$ $\Delta \eta_{\mathrm{s}} / \eta$, that the corresponding $a(\tau)$ coefficients are maximal in the region of PT. To obtain additional proofs of the validity of this viewpoint, we performed an experimental study of artificially induced electrooptic effect in TGS crystal in the temperature range of $30-65^{\circ} \mathrm{C}$. This investigation was carried out in the same arrangement as was done for the same effect induced by spontaneous polarization. External electric field of $E \approx 3.5 \mathrm{kV} / \mathrm{cm}$ magnitude was applied to the sample at different temperatures along the [010]-direction of spontaneous polarization $P_{\mathrm{s}}$, and the corresponding induced increments of the retardation $\Delta D_{\mathrm{e}} / D$ were measured. The maximum-like $\Delta D_{\mathrm{e}} / D$ temperature dependence obtained (figure 4) correlates well with the temperature dependence of $a(\tau)$. This maximum-like character of the coefficient mentioned is connected with the non-equality of $2 \beta<1$.

The results obtained can be considered from another viewpoint. Analysis of the 
table 1 testifies to certain segregation of the [010] direction of spontaneous polarization. Among the temperature changes of spontaneous increments $\Delta l_{i e}$ and $\Delta \eta_{i}(i=1,2,3)$ the dependence $\Delta l_{2}(\tau)$ is characterised by the least index $2 \beta$, but the dependence $\Delta n_{2}(\tau)$ is characterised by the greatest one (table 1$)$. On the other hand, a proximity of the values $2 \beta_{2}^{(l)} \approx 2 \beta_{2}^{(\eta)}$ (table 1 ) is observed on the background of obvious inequalities of similar characteristics for the other two crystallophysic directions $\left.2 \beta_{1,3}^{(l)}>2 \beta_{1,3}^{(} \eta\right)$ (table 1 and figure 5 ).

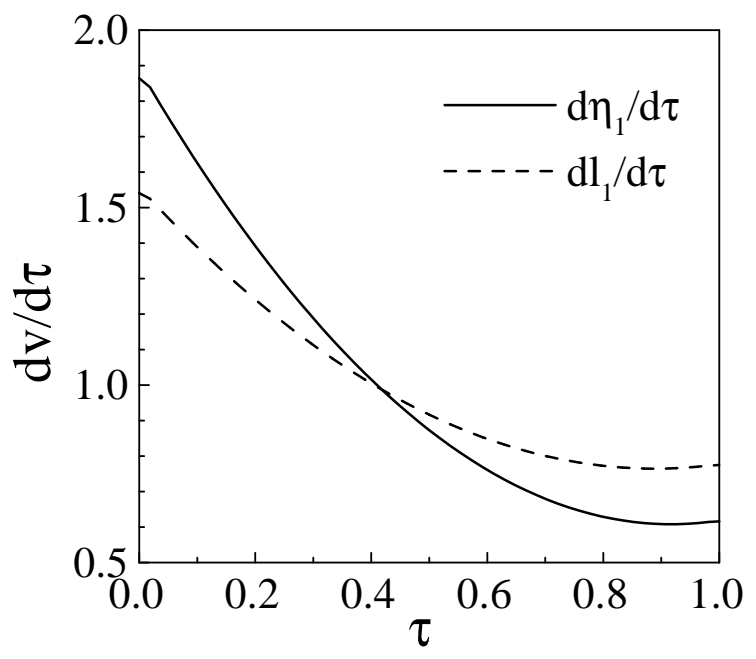

Figure 6. Temperature dependencies of derivatives for the curves, presented on figure 5.

The latter features can be interpreted as different rate of the ordering of two subsystems, one of which determines electron susceptibility and the second one is connected with geometric parameters of the crystal unit cell for the directions [100] and [001]. The equality $2 \beta_{2}^{(l)} \approx 2 \beta_{2}^{(\eta)}$ for the direction of spontaneous polarization [010] can be interpreted as high degree of correlation of the above mentioned subsystems in TGS crystal. From such a viewpoint, the observable inequalities of the indices $2 \beta_{(1,3}^{(l)}>2 \beta_{1,3}^{(\eta)}$ testify to various speeds of temperature changes of the corresponding subsystems of the crystal in the temperature range $\left(\Delta T \sim 10^{\circ} \mathrm{C}\right)$ below $\mathrm{PT}$ point. It is seen from figure 6 , where two temperature dependencies of derivatives of the values on the figure 5 are pre-

sented for two different indices $\beta_{1}$ and $\beta_{2}$. The crossing of the curves, corresponding to two different indices $\beta$ (figure 6 ), will take place in all cases, if the experimental temperature dependence of the values studied $\left(V=\Delta D_{\mathrm{s}} / D, \Delta l_{\mathrm{s}} / l, \Delta \eta_{\mathrm{s}} / \eta\right)$ is described by the power like law, $V \sim \tau^{2 \beta}$.

Such a peculiarity in the temperature dependence of different parameters can be characteristic to the ferroelectric crystals.

\section{Conclusion}

1. Deviation from the unity of the double critical index $2 \beta$ for the temperature dependencies of the changes of susceptibility and geometric thickness of TGS sample induced by spontaneous polarization is explained by significant maximum-like temperature dependencies of the coefficients of electrooptic, inverse piezooptic, and electrostriction effects.

2. An anisotropy of the critical indices $2 \beta_{i}^{(l)}$ and $2 \beta_{i}^{(\eta)}$, and nonequality $2 \beta_{i}^{(l)} \neq$ $2 \beta_{i}^{(\eta)}$ testify to different rates of temperature changes of different subsystems 
of the crystal studied, taking place in ferroelectric ordering in the range of $\Delta T \sim 10^{\circ} \mathrm{C}$ below $T_{\mathrm{c}}$.

\title{
References
}

1. Lines M.E., Glass A.M. Principles and Application of Ferroelectrics and Related Materials. Oxford, Clarendon Press, 1977.

2. Sonin A.S., Vasilevskaya A.S. Electrooptical Crystals. Moscow, Atomizdat Publ., 1971 (in Russian).

3. Lomova L.G., Sonin A.S., Regulskaya T.A. Spontaneous electrooptic effect in the triglycine sulphate single crystals. // Kristallografiya, 1968, vol. 13, No. 1, p. 90-94 (in Russian).

4. Romanyuk N.A., Kostetskii A.M., Andrievskii B.V. Dispersion of the refractive index and some characteristics of absorption spectra for the triglycine sulphate crystal's group. // Phys. Sol. Stat, 1977, vol. 19, No. 10, p. 1809-1812.

5. Malyshev A.N. Introduction into Calculational Linear Algebra. Novosibirsk, Nauka Publ., 1991 (in Russian).

6. Schmidt G., Pfannschmidt P. Piezoelektrizitat und Elektrostriktion des Triglyzinsulfats. // Phys. Stat. Sol, 1963, vol. 3, No. 12, p. 2215-2220.

\section{Критичні індекси сегнетоелектричного фазового переходу в кристалі ТГC}

\author{
О.Мищишин, Б.Андрієвський, М.Романюк
}

Львівський державний университет ім. І.Франка, 290005 Львів, вул. Кирила і Мефодія, 8

Отримано 13 січня 1999 р.

Шляхом оптичних вимірювань сегнетоелектричного фазового переходу в кристалі тригліцинсульфату за допомогою інтерферометра Жамена одержано температурні залежності оптичної різниці ходу, електронної сприйнятливості та лінійного розширення для трьох кристалофізичних напрямків. Температурні залежності спонтанних змін досліджуваних характеристик в області 39-49 ${ }^{\circ} \mathrm{C}$ апроксимовані степеневими залежностями $Y \sim \tau^{2 \beta}$ з подвійними критичними індексами $2 \beta=0.87-0.95$. Відмінність $2 \beta$ від одиниці пояснюється суттєвою температурною залежністю поблизу точки фазового переходу коефіцієнтів електрооптичного, оберненого п'єзоелектричного ефектів та електрострикції.

Ключові слова: сегнетоелектрики, фазові переходи, оптичні властивості, критичні індекси

PACS: $77.80 . \mathrm{Bh}, 77.84 . \mathrm{Fa}, 78.20 . \mathrm{Ci}$ 